\title{
Parental cultural models and resources for understanding mathematical achievement in culturally diverse school settings
}

\author{
Sarah Crafter
}

Published online: 6 November 2011

(C) Springer Science+Business Media B.V. 2011

\begin{abstract}
This paper proposes that the theoretical concept of cultural models can offer useful insights into parental involvement in their child's mathematical achievement and the resources they use to go about gaining information in culturally diverse learning settings. This examination takes place within a cultural-developmental framework and draws on the notion of cultural models to explicate parental understandings of their child's mathematics achievement and what resources are used to make sense of this. Three parental resources are scrutinized: (a) the teacher, (b) examination test results, and (c) constructions of child development. The interviews with 22 parents revealed some ambiguity around the interpretation of these resources by the parent, which was often the result of incongruent cultural models held between the home and the school. The resources mentioned are often perceived as being unambiguous but show themselves instead to be highly interpretive because of the diversity of cultural models in existence in culturally diverse settings. Parents who are in minority or marginalized positions tend to have difficulties in interpreting cultural models held by school, thereby disempowering them to be parentally involved in the way the school would like.
\end{abstract}

Keywords Parents $\cdot$ Resources $\cdot$ Mathematics learning $\cdot$ Cultural models $\cdot$ Cultural diversity

\section{Parental involvement and mathematics learning}

Within the English school system, like many other countries around the world, there has been a strong emphasis on testing and measurable outcomes for success in school. The

Sarah Crafter is also a member of the EMiCS group Educació Matemàtica i Context Sociocultural Mathematics Education and Sociocultural Context-, a research granted by the Direcció General de Recerca General Directorate of Research- of the Catalan Government (ref: SGR2009 00590). She participates in two of the research projects of the group EMiCS, EDU2010-15373 funded by the Dirección General de Investigación -General Directorate of Research- of the Spanish Government and RecerCaixa 2010-2 funded by ACUP and Fundació LaCaixa, a private foundation.

S. Crafter $(\bowtie)$

Division of Psychology, University of Northampton, Boughton Green Road, Northampton,

Northamptonshire NN2 7AL, UK

e-mail: sarah.crafter@northampton.ac.uk 
introduction of nationwide testing in core subjects like mathematics led to a greater pressure for parents to be involved in their children's school education (Bryans, 1989). However, evidence that parental involvement helps with children's achievement is mixed. Educational and political reform espouses overall support for parental involvement (Williams, 2008) whilst academic and practitioner-based studies suggests the picture is more complex owing to different forms of parental involvement (Georgiou, 1996), complexities surrounding homework (Cooper, 1989; Farrow, Tymms, \& Henderson, 1999), or home/school differences (Kim, 2009). In terms of a specific focus on mathematics learning, a meta-analysis of literature on parental involvement showed a negative relationship between parental involvement and mathematics achievement (Patall, Cooper, \& Civey Robinson, 2008). Moreover, research on parental involvement in learning largely ignores the fact that schools are populated with pupils (and in turn their parents) who come from many different cultural backgrounds (Crozier, 2001). A number of studies have now found that social, economic, and ethnic minority status does impact on parents' understandings of their children's mathematics learning owing to their own past experiences, education in another country, or changes to methods/strategies in the curriculum (McMullen \& Abreu, 2011; Jackson \& Remillard, 2005; O'Toole \& Abreu, 2005; Abreu, 2008). The aim of this article is to explore the ways in which the theoretical notion of cultural models can provide insights into the resources parents use to understand their child's mathematics achievement in culturally diverse settings.

Within the academic literature on parental involvement, those with minority, marginalized or "peripheral voices" (Hanafin \& Lynch, 2002) have been given some attention but this literature rarely focuses on mathematics learning. The pitting of one ethnic/class group over another has tended to overshadow the sociocultural composites of school practices or the "gaps" in cultural understandings of what counts as mathematics learning. The current political position is to play down cultural influences on home learning (see Williams, 2008) whilst models of the "peripheral" parent as "deficient" continue to prevail. This paper seeks to challenge this "deficient" model of the parent alongside other commentators who engage in more general debates about educational diversity (Cole, 1998; Crozier \& Davies, 2007) and those who address diversity in mathematics learning in particular (such as Andrews \& Yee, 2006; Hughes \& Pollard, 2006; González, Moll, \& Amanti, 2005).

The prevailing view that mathematics is a culture-free subject has been ardently questioned by those studying mathematics learning at home and school (Abreu, 1995; González et al., 2005; Street, Baker, \& Tomlin, 2005). Like Civil, Planas and Quintos (2005) the perspective taken in this paper is that the mathematical values and practices experienced in the home may not be those shared by the school. As a consequence, children's experiences of mathematics at home and school may be quite different. In most instances, the moot point is that parents and children are expected to share the same worldview of number as the teacher/school (Bauchspies, 2005). The "colonization" of the home by school practices does not attempt to reflect or value family practice but marginalizes practices which are not represented by white, middle-class groups (Edwards \& Warin, 1999).

However, this phenomenon is not something that is just experienced at the cognitive or strategy level of mathematics learning. The way in which mathematics is represented in the home might be quite different from that of school because of parents' own educational pasts (O’Toole \& Abreu, 2005; McMullen \& Abreu, 2011), major changes to the curriculum since parents own schooling, and the introduction of multiple mathematical strategies (Patall et al., 2008). Mathematics learning, both in the classroom and in the community are tied up with ideas around what parents should be involved in at home (Gallimore \& Goldenberg, 2001) representations of what counts as mathematics (Abreu \& Cline, 2005) 
and normative expectations (Gorgorió \& Planas, 2001; Gorgorió \& Abreu, 2009). These notions leads one to wonder how parents from culturally diverse communities make sense of their child's mathematics learning. Institutional systems like school are guided by agerelated norms whereby children are expected to reach certain achievement outcomes by particular development stages. In terms of children's learning achievements this leads to singular pathways of development, which are then considered "appropriate" or "correct" (Burman, 2008). As such, expectations for children's achievement are "normed" against particular developmental milestones (Fleer, 2006). How parents gain an understanding of these expectations is less clear.

It is argued here that parental ideas around what counts as learning either at home or school, or what age is appropriate for particular forms of learning may not be shared by the school (Crafter, 2009) or their children (see Abreu \& Cline, 2008). Home learning practices are influenced by parents' constructions of the child and the child's perceived capabilities (Solomon, Warin, \& Lewis, 2002). As stated above though, the "story" promoted through institutional systems like school reflects both a dominating and particular way of looking at children's learning, which suggests there are singular pathways to development. The agerelated institutional systematization and industrialization in countries like England coincided, and this coincidence essentially reflects White middle-class rearing practices promoted through subject areas like developmental psychology and education studies (Rogoff, 2003). With rigid inflexibility, these systems fail to take into account increasing levels of migration or the challenges faced by cultural diversity in schools.

Parents, on the other hand, operate in ways with which they are most familiar, to try and make sense of the child's successes (or failures) at school. For example, Gallimore and Goldenberg (1993) reviewed a series of studies in which they had investigated literacy practices of American-born Latino families. They found that a key factor in the way the activities were framed was the parents' representations of school literacy. They found that "as soon as the parents construe an activity as the "teaching of literacy," their prevailing concept of literary development is activated, driving the interaction and determining the script-in-use" (pp. 328-329). For instance, they found that parents overemphasized correct answers (e.g., reading a word accurately) to the detriment of reading for meaning. It is proposed that there are grounds to speculate that similar subtle processes may be in operation regarding the relationship between home and school mathematical practices (Street et al., 2005). In a later study, Gallimore and Goldenberg (2001) also found that Latino parents felt that their primary function at home was to teach moral values to their children, not school-based knowledge.

In the next section, I present the theoretical concepts of cultural models developed by Gallimore and Goldenberg (2001) and parental resources to outline how parents come to know about their child's mathematical achievement. I argue that parents are privy to limited amounts of information about their child's school life, including their child's mathematics learning, and therefore seek other avenues for constructing meaning from an environment from which they are largely excluded. When parents do try to make sense of their child's mathematics achievement, they utilize and incorporate a variety of resources within the boundaries of particular cultural models.

\section{Cultural models, resources, and representations of achievement}

This paper examines how the notion of cultural models can provide insights into the resources parents use to understand their child's mathematics achievement in culturally 
diverse settings. Parental understanding is both created and reconstructed from cultural models, which form the basis of meanings derived in a particular setting (Gee, 2008). For example, when faced with new experiences and meanings the parent will draw on an existing cultural model as a form of sense-making. These experiences may reconstruct a previously held cultural model and can be viewed as a process, not a product (Holland, 1997 ) in that they are constantly open to change and negotiation.

Cultural models are understood to be shared, recognized and transmitted internal representations which link to external actions and representations. The individual often assumes a shared understanding of the ways the world works, or should work, and they are often hidden or unrecognizable to the self. A cultural model is described as "encoded shared environmental and event interpretations, what is valued and ideal, what settings should be enacted and avoided, who should participate, the rules of interaction, and the purpose of the interactions" (Gallimore \& Goldenberg, 2001, p. 47).

Cultural models are a form of patterning which help to classify ones experiences (Gee, 1999). These patterns are situated meanings which are neither very general nor specific but tend to relate closely to a person's own experiences and sociocultural context (Pérez Campos, 2004). This is applicable to mathematical learning because our learning comes with a knowledge structure which is a reflection of our family or community practices (Abreu, 2008). Specific cultural settings, like home and school, put constraints on the kinds of cultural models that parents are engaged with. For example, mathematical-based home activities such as counting the items on a shopping list with the help of a child, or using cooking to help with number, will only take place in some home settings and are linked to particular cultural models about home mathematics learning. These cultural models happen to be highly valued in the school setting. However, not all parents share the same resources with the school and therefore may not incorporate these kinds of practices into their cultural models. Equally, teachers and schools do not always have an awareness of the many resources available in culturally diverse home situations (Civil \& Andrade, 2003; Civil et al., 2005).

Resource is a concept that refers to the way in which the individual is simultaneously a seeker and provider of meaning. The classical definition of a resource suggests it is something which one resorts to for aid or support. A "source" provides information, often in the form of a book or person. Parents operate in both of these ways to explore and examine the educational world of their child. Civil and Andrade (2003) and Jackson and Remillard (2005) talk about "intellectual resources" to show the varied home mathematical practices with which parents engage. I argue that resources are not just used at the level of knowledge or strategy (cognitive resources) but also at the level of meanings and representations (social resources; Zittoun, 2004; Zittoun, 2006).

Some resources may appear very concrete or tangible, meaning that they have their basis in something "factual" or "knowledgeable." For example, examination results are often treated as being a true reflection of competency, or the teacher is seen as providing accurate knowledge about a child's achievement and this resource could therefore be described as concrete. Other resources are intangible, meaning that the ideas are abstract or representational. In the context of this paper, an example of an intangible resource used to understand a child's mathematical achievement is the parents' construction of child development.

However, it is proposed in this paper that whether resources are "tangible" or "intangible" they can be reinterpreted in light of parents" own cultural models which may, or may not, be closely aligned with the teacher/school, particularly in culturally diverse settings. This paper seeks to use these theoretical concepts to try and make sense of parents' talk of their child's mathematical achievement. 


\section{The study of parental cultural models and resources}

The 22 parents participating in this study had children in primary schools (ages 5-11 years) situated in a town in the South East of England. Eleven of the 22 parents were from ethnic minority backgrounds and the remaining participants were White and British born. The ethnic categories of the parents interviewed were self-assigned. The children are characterized as being either high achievers (HA) or low achievers (LA) in mathematics and were placed as such by their teachers using examination results data and teachers' own representations of achievement status. Data collection took place in three multiethnic schools that are known as school A (mainly White), school B (ethnically mixed), and school C (mainly South Asian-Indian, Pakistani, and Bangladeshi). Data from parents was collected using the episodic interview (Flick, 2000), a method that assumes a shared common knowledge on behalf of the participants about the subject under study. It specifically facilitates the exploration of meanings, representations and experiences by drawing on two forms of knowledge - episodic and semantic. Episodic knowledge is knowledge that is linked to concrete circumstances or situations. Semantic knowledge is abstract and decontextualised (such as opinions). When these forms of knowledge are combined the participant is able to choose salient concrete situations alongside recounting their subjective relevance. The interview questions are thus posed in two parts:

Does your child bring any maths homework home? Can you tell me about what he/she has been doing recently?

Do you know how well [..] is doing at school? And can you describe to me how you found out?

The procedure for analyzing the interviews was borrowed from the work of Flick (2006) and is based upon the analysis of themes to look for patterns across the data. First the interview transcripts were read thoroughly and codes were generated and identified from the data. These codes were then placed into associated themes (Braun \& Clarke, 2006). The thematic presentation in this paper is parents' constructions of their child's achievement. In their accounts, parents utilized a varied number of resources to help them construct an understanding of their child's achievement. The three dominating resources were coded as: (a) the teacher, (b) exam test results, and (c) constructions of child development.

Although the study was specifically about mathematics, parents within the sample used this opportunity to talk about their child's education as a whole and therefore the data is highly inclusive of other educational issues. For parents, constructing meaning in relation to their children's mathematics education is like fixing together the pieces of a puzzle and this is managed in a holistic way.

\section{Cultural models and resources for understanding the child's achievement}

\subsection{Using the teacher as a resource}

As a key figure in the educational world of the child, it is not surprising that the parents in this study often spoke about the teacher as a resource of information about mathematics achievement. Parents of high achieving children were more likely to mention using the teacher as a resource, and this applied to the White British parents as well. Cultural models vary according to our belonging to cultural communities and are a reflection of one's 
sociocultural membership (Gee, 2001). Therefore, White British parents of high achieving children were more likely to use the teacher as a resource because of shared cultural models of education, teaching and learning with the school. The discrepancies and conflicts in value positions between home and school for those who do not share cultural models with the school have been well documented by Hedegaard (2005) and dominant cultural models often marginalize non-mainstream groups (Gee, 2008). This analysis will demonstrate that minority or marginalized parents do not necessarily share the same cultural models of their child's achievement with the school, often unconsciously (Gee, 2001). Equally, the ways they draw on the resources to make sense of cultural models are used in different ways to those parents who are not in minority of marginalized positions. One of the ways in which parents attempt to make sense of their child's achievement is through communication with the teacher.

On the whole, parents' communication with teachers tended to take place during the parent-teacher consultation evening on a twice-yearly basis. In the UK, parents are invited to the school to discuss the progress of the child and this process is often akin to doctor-patient consultations where teachers provide an uninterrupted "diagnosis" of performance (Maclure \& Walker, 2000). Communication between parents and teachers surrounding achievement is complex, and teachers couch many of their descriptions of the child to parents using specialist vocabularies or "teacher talk" whereby descriptions could connote two different meanings. For example, if a child is described as having "leadership qualities" this can also be interpreted as "the child is bossy." "Teacher talk" can produce a discrepancy between the teacher's discussion of the child's mathematics achievement and the parents' understanding of that achievement. However, to understand that a discrepancy has occurred, the parent must have the resources to understand that they may be expected to reinterpret the "teacher talk." This would require the parent to be conscious of the existence of a cultural model whereby teachers are not able to explicitly state if a child is not achieving well. An example of this can be found in this quote from a teacher who is also a parent. She describes how her own role as a teacher provided her with the resources to re-interpret "teacher talk" about her own son. She was not the only teacher who described this resource when talking about their role as a parent-teacher:

Jane: They can't pull the wool over your eyes [an expression to connote being misled] once you work in education. If you go for a parents evening they don't give you the woolly airy fairy; they don't give you the estate agents talk, they give you "Alex is not doing well at this or yes he's doing well at that" they don't pull the wool over your eyes.

Sarah: So teachers are a bit more straight with you?

Jane: Yeah, they don't, they don't pull the wool over you. They talk to you because you know the terminology and everything. It's not like, when I write reports we have to write "if concentration was higher he would do better" you know [meaning] "if so-and-so applied themselves," in other words "if so-and-so didn't behave like an absolute little shit." (Teacher: school A, 5/6-year olds, LA)

This teacher's cultural model, her ability to encode meanings and interpretations (Gallimore \& Goldenberg, 2001), stem from her role as a teacher which has allowed her to become aware of the hidden messages in the accounts of professional vocabularies. Jane also described the institutional pressure upon her to create a positive discourse about the children, which can fuel greater dissonance in the cultural models of parents who do not have the resources to 
interpret hidden meanings. It was invariably minority or marginalized parents who did not have these resources.

An example can be seen in this interview extract with Rajesh's mother, an Indian mother who recalled to me a moment during a parents' consultation when she asked the teacher, "how's he getting on [in mathematics], will he be alright?" and Rajesh's mother described how the teacher replied:

Rajesh's mother: "he'll be fine, no point to worry or anything... if he just carries on the way he's doing, he's fine" (Indian mother: 6/7 years, LA)

The discrepancy is evident in the fact that the teacher described Rajesh to me as a low achieving child in mathematics. Rajesh was placed in the lowest mathematics achievement "set" at school and worked at a level below what was expected for his age group. He still struggled to undertake calculations with numbers below ten, whilst curriculum guidelines stipulated that children of his age should be capable of working with numbers up to 20 . Cultural models are loaded with meanings that may be interpreted differently depending on the experiential resources at your disposal, which in turn are born out of your own cultural experiences (Gee, 2001). The difficulty here is with the interpretation of the word "fine" which in the UK covers a wide range of meanings. In its literal sense to do "fine" could be to do very well but colloquially sits below being "good" and so suggests doing "less-well" than average. Rajesh's mother held a cultural model of "teachers talk" as being factual or concrete and consequently interpreted the teacher's words with a literal meaning.

This point is again illustrated by another parent, Fazain's mother, who reported a similar conversation she had with a teacher at her son's school:

Fazain's mother: Mr. Headworth, he was saying that he is really good in maths because he comes home and you know, because I improve my maths, you know, a lot. So I teach him, and he's coming really good, he's top in his class (Pakistani mother: 10/11 years, LA)

Fazain was by no means top of his class and was described to me by his classroom teacher as a low-achieving child. Again, this mother's own cultural model of the teacher as a resource of information about her child's mathematics achievement is concrete. People use their cultural models creatively by borrowing from a variety of experiences to reconstruct a new model (Pérez Campos, 2004). This parent has a resource which provides what she must perceive as a tangible contribution to this cultural model - she took mathematics lessons herself to improve her own mathematics so she could help her son. This is evidence of a direct link between certain practices, her experiences, and her cultural model. In other words, she takes a course to improve her own mathematics, this improves her son's mathematics, and this cultural model of achievement is endorsed through "teacher talk."

It is hard to say based on this data alone, but perhaps this is a peculiarly British phenomenon and both Rajesh's and Fazain's mothers do not understand this cultural model around "teacher talk" because they were educated in India and Pakistan respectively. There has also been strong evidence to suggest that social class plays a role in cultural models of "success" (see D’Andrade, 1984; Strauss, 1992). While social class was not measured in this study, there was evidence that parents who were not in a minority or marginalized position had resources which allowed them to challenge or recognize incongruent cultural models provided by the teacher. Just such an example could be provided by Michael's mother, a White British parent whose son was described as being high achieving in mathematics. 
Michael's mother described a negative parent-teacher consultation she had experienced. In his first 2 years of schooling, Michael's parents had always been told that he was achieving well. At the most recent parent-teacher consultation, Michael's parents were surprised to be told that he was not doing as well as the others. This challenged the cultural model of her son's achievement held by the mother at that time. In consequence to the challenge of a previously steadfast cultural model of her son's mathematical achievement, this mother questioned the teacher's judgment:

Michael's mother: As I say, this consultation with Mrs. Edwards didn't even sound like Michael... I thought, she doesn't know this child at all, doesn't even sound like him... and I remember being so cross... and I said to [the head teacher] "what does this child have to do to get any praise?" because I thought it was so unfair. Because he was working hard and yet there wasn't a single thing said that was positive. (White British: 6/7 years, HA)

Although the teacher was mentioned as a resource of information by all the parents sampled, as a means of understanding their child's achievement, parents may challenge the cultural model if it runs counter to previously well-established models of understanding. Michael's mother had at her disposal other resources to help her understand his achievement, such as conversations with other teachers in the past and discussions with other parents in the playground. These conversations and experiences can be described as event interpretations. The use of event interpretations, or external actions, is described by Gallimore and Goldenberg (2001) as one of the features of the internalization of cultural models. The children in Michael's school were put into ability groupings and this mother did describe conversations with other parents about which "set" he was placed in. Since he was placed in the highest ability set for mathematics, and then was put on a high achieving table within this set, she felt confident in resisting the teacher's models of his achievement. Cultural models are described as being partial or inconsistent because they are so intricately linked with social and cultural values, experiences, power and status (Gee, 2001). It is not uncommon for individuals to have inconsistencies and contradictions to their own cultural models but in the case of Michael's mother, there is inconsistency between her own and the teacher's cultural model about her son's mathematics achievement.

On the whole, parents placed a great deal of emphasis and importance on the teacher's judgment of their child's achievement without always realizing that teachers' vocabularies can be framed to connote multiple meanings. One might speculate that these discrepancies are even more problematic for parents who experience difficulties in accessing or communicating with the school (such as ethnic minority parents, working class parents, or parents of low achievers). Mothers like those of Rajesh and Fazain appear to hold cultural models which take at face value the "no-need-to-worry" teacher talk. This is unsurprising when models of success are more desirable and the teacher is considered the key authority. Using the teacher as a resource requires that conversations take place in a setting which is rigidly framed by a White middle-class institutional structure (Rogoff, 2003) and as such, teachers are in a powerful position. Michael's mother has fewer qualms about challenging the cultural model presented by the teacher as it conflicts with her own model of her son's mathematics success. Thus she has particular resources, namely a strong cultural model of her own based on conversations with previous teachers (among other things like test results, etc.) to challenge the teacher's perspective. 
It was suggested earlier that using the teacher as a resource of information could be perceived by some parents as tangible or concrete and yet "teacher talk" is itself a cultural model which parents need other resources to interpret. Parents' constructions of their child's achievement are also open to reinterpretation because they too have the potential to be reconstructed in view of their own cultural models and settings.

\subsection{Using examination test results as a means of understanding achievement}

At the time of data collection, examination results from Standard Assessment Tests (SATs) were conducted with years 2 (6/7 years of age) and 6 children (10/11 years of age) and then widely published for public consumption. Year 2 children no longer take SATs examinations for public publication in England. However, the publishing of results by school is a widely held practice internationally and is often fraught with tensions and difficulties (Lange \& Meaney, 2011). It is perhaps not surprising that these examinations were at the forefront of these parents' minds and consequently, regularly mentioned as a resource for understanding their child's mathematics achievement. Parents of high achieving children were most likely to talk about examination results in relation to their child's mathematics achievement, although there was little difference between the White British and ethnic minority parents. In principle, examination results can be perceived as a concrete means of understanding achievement. Yet how the parents came to understand or use these tests results for assessing their child's achievement and construct subsequent cultural models was open to considerable interpretation.

All the parents in this study were at school when a very different system was in place and some of the parents were not educated in the UK. For most of the parents, tests in their own schooling were scored using a well-established A-G classification and it is understandable that parents also used their own educational experiences to make sense of their child's learning (O'Toole \& Abreu, 2005; McMullen \& Abreu, 2011). However, changes brought about by educational reform meant that test scores were now graded using levels 1-6, rather than A-G classifications which parents were familiar with. Furthermore, within each level the child was further rated as an "a" "b," or "c," with "a" being the highest classification within a level. To complicate matters further, the levels did not correspond with the children's year group; for example, a child in year 2 (ages 6/7 years) was expected to achieve a level 2. However, a child in year 6 (ages, 10/11 years) was expected to reach a level 4. Once again though, parents of high achieving children in this sample had a clearer idea of the scoring system used for the SATs. Why this should be the case is uncertain, since the scoring was new for all parents. It is likely that these parents were confident in accessing resources like the teacher, websites and shop-bought information books. A similar phenomenon was found in a study on middle-class American parenting by Harkness, Super and Keefer (1992). Middle-class parents were more likely to seek out "formal theories" of child rearing from professional books than rely on "folk psychology" from relatives.

The majority of parents who knew that the SATs examinations were taking place had negative feelings about the tests. Some thought the children were too young for testing and this ran counter to their cultural models of appropriate child development practices. Others felt that the SATs examinations were for the school's benefit, and not for the child since results were published publicly and were used to measure the school's success. Dale's father questioned the resource as a means of understanding his son's mathematical achievement: 
Dale's father: I find going into school reinforces my idea that they put you in a pigeonhole at the earliest opportunity; that's the line, you're this side of the line, you'll always be the worst. Well, all right, he's a couple of digits down on a maths test, it's not the end of the world but to listen to them talk sometimes; is that because of the concern for Dale or is it because they're concerned the school is going to get a bad report because the stats [statistics] are down... and I sometimes wonder exactly what it's for, this sort of test thing (White British: 10/11 years, LA)

Cultural models are complex in their organization and there are smaller models that might be set, or linked to, larger models (Gee, 2001). In this case, the larger model concerns the use of formal examination testing in relation to models of child development and age. This in turn might trigger smaller models; such as the notion that it is not for the child's benefit that the examinations are conducted. Dale's father adopted this cultural model in this segment of the interview and he was not alone in this opinion among this sample. Most of these parents maintained that examination results provided data for the school and were motivated at the political level but were not geared towards helping the individual child. These models could have developed from a variety of sources, conscious or unconscious, such as the media and interactions with other individuals (Gee, 2008). Incidentally, the skepticism around national testing was privately shared by some of the teachers sampled in this research study also. This father raised the political dimensions to examination testing when I asked him how he felt about the exams:

Louise's father: I feel it puts the schools under a lot of pressure, unnecessary pressure. We used to do end of year exams at school, but ours weren't pressured from all directions. I feel they have to concentrate on far more than they should do. We used to do the end of year exams every year, so they knew how we were progressing, but they didn't have to tell anyone else. I think that's wrong where they have to tell the government.

Sarah: Because you feel it puts the school under pressure?

Louise's father: And they try and fiddle it, they try and cram. They don't do a broad spectrum of each subject (White British father: 10/11 years, HA).

This father uses his own educational past history to support a cultural model that examinations are useful to the school if they are simply used to measure progress. His skepticism comes from implications for political involvement in the publication of results and how this filters down to the child in the form of cramming to pass tests.

One exception to the widely negative model of testing was held by Rajesh's mother whose cultural model supposed testing to be a useful resource for helping with her child's learning. Unlike Louise's father above, her cultural model did not trigger a wider political critique of mathematics testing at a young age. She felt the tests would offer insights into further achievement progress:

Rajesh's mother: I reckon tests are good because it will show him what he needs to go further on and what he needs to learn... I think he's going to have tests his whole life so he might as well start now... they're not going to judge the kid, if he's bad or anything it just means he needs more help which is good in a way (Indian mother: $5 / 6$ years, LA) 
There is something very literal or concrete about how this mother interprets the use of testing. She holds a straightforward and commonsensical model of testing which supposes that there would be some kind of positive feedback from the tests, which would help her son realize his mistakes and improve. However, once the final examinations had been finished, none of the schools in this sample revisited the papers or appeared to use the data from the test to build on the mathematical weaknesses of individual students. Perhaps Rajesh's mother held a more positive cultural model around institutional testing because she believed that this system would provide her son with feedback on his mathematics. Earlier on in the analysis it was mentioned that cultural models are loaded with meanings, which are subject to variability according to cultural membership and experience (Gee, 2001). It was also argued that parents in minority or marginalized positions are less likely to question the meanings associated with school practices. Rajesh's mother's cultural model on examination testing neither challenges nor recognizes and incongruence in the school's use of testing, as it did for many other parents.

With two exceptions, the parents of low achieving children had more negative feelings towards the examinations than parents of high achieving children. Parents here were concerned about seeing their children fail, something that is more likely to happen to the low achieving children. Parents' difficulties in interpreting the SATs mathematics examination results meant that even as a "concrete" resource of information about the child's achievement, examination results could hold their own interpretive problems. Cultural models are made up of wishes, beliefs and desires and therefore have an emotional aspect to them (D'Andrade, 1995). No one wishes or desires their child to do poorly in their mathematics learning and perhaps because of this, will resist or avoid something that will be received as unwelcome.

Test results are often used as a form of concrete information, meaning that they are taken as a "true" reflection of a student's achievement, even by skeptics (for example, teachers in this sample often looked at test scores as a reflection of an individual's achievement with skepticism whilst simultaneously using them to guide putting children into achievement sets). Parents also spoke about how well or poorly they thought their child had done, or would do, in the examination tests. It is argued here that even when test scores appear to be a concrete resource for parents to help them understand their child's achievement, the parents' cultural models can make what seems tangible into some intangible. Changes to the scoring system and parental models about the purpose of the tests make these a more unreliable resource than one might suppose.

\subsection{Models of child development as resources for understanding achievement}

One other piece of the educational puzzle, perhaps built upon the most symbolic of all the resources for understanding achievement, was the use of models of child development. Juxtapositioned against the need to understand mathematics achievement was the belief that the children were very much in the early stages of their own development. Schools also hold firm views of child development in the way that achievement and classroom content is "normed" against particular developmental milestones (Rogoff, 2003; Fleer, 2006; Burman, 2008). Cultural models are linked to cultural practices; or in other words, in everyday activities and what we do. Other "bits and pieces" of cultural models "are in peoples' heads" according to Gee (2001, p. 43) or as Gallimore and Goldenberg (2001) describe them, "tools for the mind" (p. 47). Cultural models are sometimes "rough and ready" theories about how the world works, and as such are a particularly useful concept for understanding how parents conceptualize child development. Cultural models around which 
school-based child development norms have been developed are often at odds with the cultural models of child development held by parents. Parents in this sample tended to view their children as being very young because they were in primary school (spanning the ages of 4-11 years). As a consequence of these dissonant models of child development, tensions were created between home and school.

Rajesh's mother displayed some of this dissonance between her own model of child development and her desire for her child to be successful early in life and the expectations of school:

Rajesh's mother: But then I'm thinking like, his education is important at the moment but it's still a bit of a laugh for him so I don't really want to burden, like I don't want to be like a fussy parent saying I'm pushing him or something... but at the moment you think he's only seven, you don't really want to push him too much, cause' you're stuck in the middle. Then you think if he has a good start now then he'll have a good start, you know. I don't know, it's a bit difficult (Indian: 6/7 years, LA)

Her conflicting model of appropriate parenting and educational expectations for achievement are both tied in with her identity as a good parent. Contained within the quote are three messages which are no doubt conflicting but lead back to her model of child development as the resource of understanding. She does value education and considers it important, but for a boy of 7 years old it should be fun. She was also worried about being perceived as "pushy" if she broke away from her own cultural model of child development. However, Rajesh's mother seems to be aware that her own cultural model of child development is dissonant from the expectations of the school because she describes being "stuck in the middle." School as an institution in England, it can be argued, relies heavily on constructs established by stage-related theories, which often dominate subjects like developmental and educational psychology (Burman, 2008). "Stage" models of development also influenced parents' cultural knowledge of parenting (Harkness, Super, \& Keefer, 1992). Parental models of child development described in this sample of parents were not necessarily congruent with the models held by the teachers. One of the year-2 teachers, Richard, in School B told me:

Richard: I still think some parents haven't quite caught onto the idea that they're seven, so we should be expecting quite a lot of them. Their [the parents] expectations of what a child can do isn't as high as our expectations... (school B, 6/7 years, mixed achievement)

Here, Richard refers to the way in which the cultural model of child development held by the school might be in conflict with those of the parents. Cultural models can take on an evaluative quality, especially if their intangibility leads to dissonance, as they are often consciously or unconsciously used to make some kind of judgment (Gee, 2001). Even when parents appeared to have a keen awareness of the cultural models held by the school, parents' own models of child development could still challenge these. Simon's mother drew on her own experiences as a school child to understand the anomalies between her own models of child development and what her son was experiencing:

Simon's mother: I just think that he's seven, he's in the infants and if I related to when I was in the infants, we never brought homework home until; I think we just 
had reading. And part of me thinks they're just children, let them be children, you know, if they're happy they'll be learning and I don't want too much pressure on him really (White British: 6/7 years, HA)

Discussions about how models of child development might play a role in affecting children's learning raise questions around what this might mean for mathematics at home and school. The differences appeared in the subtle kinds of mathematical practices that parents were (or were not) engaging in. For example, whilst some parents of children in year 2 (ages 6/7 years) were playing fairly complex games with dominoes or using two dice for playing snakes and ladders, or chess, others were still giving their children dot-to-dot ${ }^{1}$ books with numbers up to 10 -in school curriculum terms the latter would be working below their expected developmental level. In other words, parents' cultural models of child development also influenced what they "do" as well as how they "think." As Gallimore and Goldenberg (2001) stated when describing the concept of cultural models, it is as much about activity as it is about representation, beliefs or values. A recurrent idea running through parents' models of child development was that of learning as a progressive activity. Learning was viewed by many of the parents as a building block, which develops with the child. The crux of the problem is that parents' stage-related views on child development are more varied than one might expect and as a consequence so are the mathematical activities that they engage in with their children. Moreover, it was not unusual for parents' cultural models of child development to be dissonant from the cultural models of child development widely held in schools.

\section{Reflections on cultural models and resources in mathematics learning}

This paper has taken the theoretical framework of cultural models, as it is presented by Gallimore and Goldenberg (2001) and Gee (2001, 2008), along with the notion of resources to try and make sense of how parents understand their child's mathematics achievement. Gallimore and Goldenberg's original formulation of cultural models taken from their 2001 paper was considered useful because it was specifically used to try and connect ethnic minority home learning with school improvement research. More importantly, this model provided a conceptual framework that avoids looking at minority or marginalized parents as "deficient" in their involvement and instead incorporates cultural analyses into our understanding of parental involvement in mathematics learning. Gallimore and Goldenberg apply this framework to a study of minority literacy practices and this paper has attempted to do the same with mathematical practices. Gee's (2001) contribution to the discussion of cultural models has more conceptual depth and provides a theoretical lens to study moments of dissonance between home and school mathematics learning. Cultural models are born out of our sociocultural membership and are linked with our experiences as well as being subject to structures of power.

When the parents spoke about their children's mathematics learning they drew on much more than isolated accounts of mathematics as a subject. Parents tried to make sense of their child's mathematics experience by using both concrete and intangible (or symbolic, Zittoun, 2006) resources which fed off, and into, their cultural models. While some resources, like the teacher and examination results, might be considered fairly concrete forms of information for parents, they carried their own problems of interpretation and expectation.

\footnotetext{
${ }^{1}$ Dot-to-dot are drawings which are revealed by joining numerical points together.
} 
For example, some parents in this sample had a cultural model that allowed them to reinterpret double meanings during "teacher talk" about their child's mathematics achievement. Other parents' models led them to use the teacher as a resource in a very unchallenging or unambiguous way. Arguably, it is the minority or marginalized parents who are least likely to understand double meanings, which in turn dis-empowers them to become parentally involved in a way that the school would like. Parents who are not in minority or marginalized positions tended to have the resources to either challenge the school or recognize incongruent pieces of information. This latter group of parents was more likely to draw on a range of resources, often in a fairly critical way (e.g., the role of Government and politics), to challenge cultural models derived from school. Moreover, some of the teachers in the study were cognizant of this mismatch between cultural models of school and home.

The least tangible cultural model, constructions of child development, was born out of values, expectations, practices and past experiences. Out of all the parent interviews, child development as a resource was least likely to be shared with the school but was still a pervasive influence in the home. The parents' models of child development differed from the schools in that they perceived their children to be "very young" and therefore often underestimated what the school expected of the children in their mathematical achievement. There was also variation in the kinds of mathematical practices that parents described doing at home with their children, which often related to their construction of child development. Some parents engaged in fairly complex games of dominoes and chess (with children as young as 6/7 years) whilst others were giving their children basic dot-to-dot counting up to 10 .

On another theoretical note, cultural models and knowledge about achievement have a reciprocal influence on each other. A question may be raised about whether the cultural model is established before the representation of achievement or whether images of achievement precede the model. The use of cultural models and representations of achievement are seen as constituted from each other, in that they have the power to be transformed, reconstructed and rejected based on the resources that are utilized. In other words, new information about achievement (e.g., resourced from test examination results) may change a cultural model. On the other hand, a steadfast cultural model (e.g., resourced from representations of child development) might be resisted or rejected in light of discussions with the teacher about what a child should be able to achieve by a certain age.

Earlier in this paper, I argued that these theoretical concepts can help us gain a better understanding of parental involvement in children's mathematics learning in culturally diverse settings. Having a greater understanding of parents' mathematical cultural models could provide the mechanism to help home-school relations and increase parental involvement. When Gallimore and Goldenberg (2001) and the school they worked with sent home literacy materials, they found that parents did not always use them in the way the school planned because of the parents' cultural models of what counts as literacy homework. In other words, there was incongruence between the models of home and school around literacy. This paper has tried to demonstrate that there can also be incongruence between the models held by home and school relating to mathematics learning also. Finally, I would also argue that to work towards a better understanding of the varied cultural models held by parents from culturally diverse backgrounds requires some self-reflection about what kinds of cultural models are held by the school and the teachers within the classroom. With greater recognition of the variety of cultural models and potential for misunderstandings between home and school, this theoretical framework could be used to empower parents and schools when addressing mathematics learning. 


\section{References}

Abreu, G. de. (1995). Understanding how children experience the relationship between home and school mathematics. Mind, Culture and Activity: An International Journal, 2(2), 119-142. doi:10.1080/ 10749039509524693.

Abreu, G. de. (2008). From mathematics learning out-of-school to multicultural classrooms: A cultural psychology perspective. In L. English (Ed.), Handbook of international research in mathematics education (2nd ed., pp. 352-383). USA: Lawrence Erlbaum Associates.

Abreu, G. de., \& Cline, T. (2005). Parents' representations of their children's mathematics learning in multiethnic primary schools. British Educational Research Journal, 31(6), 697-722. doi:10.1080/ 01411920500314869.

Abreu, G. de., \& Cline, T. (2008). Schooled mathematics and cultural knowledge. In P. Murphy \& R. McCormick (Eds.), Knowledge and practice: Representations and identities (pp. 189-204). Milton Keynes: The Open University.

Andrews, J., \& Yee, W. C. (2006). Children's'funds of knowledge' and their real life activities: Two minority ethnic children learning in out-of-school contexts in the UK. Educational Review, 58(4), 435-449.

Bauchspies, W. (2005). Sharing shoes and counting years: Mathematics, colonization, and communication. In A. Chronaki \& I. Christiansen (Eds.), Challenging perspectives on mathematical classroom communication (pp. 237-259). US: Information Age Publishing.

Braun, V., \& Clarke, V. (2006). Using thematic analysis in psychology. Qualitative Research in Psychology, $3,77-10$.

Bryans, T. (1989). Parental involvement in primary schools: Contemporary issues. In S. Wolfendale (Ed.), Parental involvement: Developing networks between school, home and community. UK: Cassell Educational Limited.

Burman, E. (2008). Deconstructing developmental psychology (2nd ed.). London: Routledge.

Civil, M., \& Andrade, R. (2003). Collaborative practice with parents: The role of the researcher as a mediator. In A. Peter-Koop, V. Santos-Wagner, C. Breen, \& A. Begg (Eds.), Collaboration in teacher education: Examples from the context of mathematics education (pp. 153-168). Boston: Kluwer.

Civil, M., Planas, N., \& Quintos, B. (2005). Immigrant parents' perspectives on their children's mathematics education. Zentralblatt für Didaktik der Mathematik (ZDM), 37(2), 81-89.

Cole, M. (1998). Can cultural psychology help us to think about diversity? Mind, Culture and Activity, 5(4), 291-304. doi:10.1207/s15327884mca0504_4.

Cooper, H. (1989). Synthesis of research on homework. Educational Readership, 47, 85-91.

Crafter, S. (2009). Parental resources for understanding mathematical achievement in multiethnic settings. In Abreu, Crafter \& Gorgorió (Eds.), Proceedings from the 6th Conference of the European Society for Research in Mathematics Education, (pp. 14-22). Lyon, France. Available from: http://www.inrp.fr/ publications/edition-electronique/cerme6/wg8.pdf\#page $=15$.

Crozier, G. (2001). Excluded parents: The deracialisation of parental involvement. Race, Ethnicity and Education, 4(4), 329-341. doi:10.1080/13613320120096643.

Crozier, G., \& Davies, J. (2007). Hard to reach parents or hard to reach schools? A discussion of homeschool relations, with particular reference to Bangladeshi and Pakistani parents. British Educational Research Journal, 33(3), 295-313. doi:10.1080/01411920701243578.

D’Andrade, R. (1984). Cultural meaning systems. In R. A. Shweder \& R. A. LeVine (Eds.), Cultural theory: Essays on mind, self, and emotion (pp. 88-119). Cambridge: Cambridge University Press.

D'Andrade, R. (1995). Some propositions about the relations between culture and human cognition. In J. W. Stigler, R. A. Shweder, \& G. Herdt (Eds.), Cultural psychology: Essays on comparative human development (pp. 65-129). New York: Cambridge University Press.

Edwards, A., \& Warin, J. (1999). Parental involvement in raising the achievement of primary school pupils: Why bother? Oxford Review of Education, 25(3), 325-342.

Farrow, S., Tymms, P., \& Henderson, B. (1999). Homework and attainment in primary schools. British Educational Research Journal, 25(3), 323-341.

Fleer, M. (2006). The cultural construction of child development: Creating institutional and cultural intersubjectivity. International Journal of Early Years Education, 14(2), 127-140. doi:10.1080/ 09669760600661294.

Flick, U. (2000). Episodic interviewing. In Bauer \& Gaskell (Eds.), Qualitative researching with text, image and sound: A practical handbook (pp. 75-92). UK: Sage Publications.

Flick, U. (2006). An introduction to qualitative research. London: Sage.

Gallimore, R., \& Goldenberg, C. (1993). Activity settings of early literacy: Home and school factors in children's emergent literacy. In E. A. Forman, N. Minick, \& C. A. Stone (Eds.), Contexts for learning: Sociocultural dynamics in children's development (pp. 315-335). Oxford: Oxford University Press. 
Gallimore, R., \& Goldenberg, C. (2001). Analysing cultural models and settings to connect minority achievement and school improvement research. Educational Psychologist, 36(1), 45-56. doi:10.1207/ S15326985EP3601 5 .

Gee, J. P. (1999). An introduction to discourse analysis: Theory and method. London: Routledge.

Gee, J. P. (2001). An introduction to discourse analysis: Theory and method (3rd ed.). London: Routledge. Gee, J. P. (2008). Social linguistics and literacies: Ideology in discourses. London: Falmer Press.

Georgiou, S. N. (1996). Parental involvement: Definition and outcomes. Social Psychology of Education, 1 (3), 189-209. doi:10.1007/BF02339890.

González, N., Moll, L. C., \& Armanti, C. (2005). Funds of knowledge: Theorizing practices in households, communities, and classrooms. New Jersey: Lawrence Erlbaum.

Gorgorió, N., \& Abreu, G. de. (2009). Social representations as mediators of practice in mathematics classrooms with immigrant students. Educational Studies in Mathematics, 72(1), 61-76. doi:10.1007/ s10649-009-9183-3.

Gorgorió, N., \& Planas, N. (2001). Teaching mathematics in multilingual classrooms. Educational Studies in Mathematics, 47(1), 7-33. doi:10.1023/A:1017980828943.

Hanafin, J., \& Lynch, A. (2002). Peripheral voices: Parental involvement, social class, and educational disadvantage. British Journal of Sociology of Education, 23(1), 35-49. doi:1080/01425690120102845.

Harkness, S., Super, C. M., \& Keefer, C. H. (1992). Learning to be an American parent: How cultural models gain directive force. In R. D’Andrade \& C. Strauss (Eds.), Human motives and cultural models (pp. 163-178). Cambridge: Cambridge University Press.

Hedegaard, M. (2005). Strategies for dealing with conflicts in value positions between home and school: Influences on ethnic minority students' development of motives and identity. Culture and Psychology, 11 (2), 187-205. doi:10.1177/1354067X05052351.

Holland, D. (1997). How cultural systems become desire: A case study of American romance. In R. D’Andrade \& C. Strauss (Eds.), Human motives and cultural models (pp. 61-89). Cambridge: Cambridge University Press.

Hughes, M., \& Pollard, A. (2006). Home-school knowledge exchange in context. Educational Review, 58 (4), 385-39.

Jackson, K., \& Remillard, J. T. (2005). Rethinking parent involvement: African American mothers construct their roles in the mathematics education of their children. School Community Journal, 15(1), 51.

Kim, Y. (2009). Minority parental involvement and school barriers: Moving the focus away from deficiencies of parents. Educational Research Review, 4(2), 80-102. doi:10.1016/j.edurev.20009.02.003.

Lange, T. \& Meaney, T. (2011). Becoming disadvantaged: Public discourse around national testing. Congress of the European Society for Research in Mathematics Education (9-13 February) Poland, Rzeszów.

Maclure, M., \& Walker, B. M. (2000). Disenchanted evenings: The social organization of talk in parentteacher consultations in UK secondary schools. British Journal of Sociology of Education, 21, 5-25.

McMullen, R., \& Abreu, G. de. (2011). Mothers' experiences of their children's school mathematics at home: The impact of being a mother-teacher. Research in Mathematics Education, 13(1), 59-74.

O'Toole, S., \& Abreu, G. de. (2005). Parents' past experiences as resources for mediation in the child's current mathematical learning. European Journal of Psychology of Education, 20(1), 75-89. doi:10.1007/BF03173212.

Patall, E. A., Cooper, H., \& Civey Robinson, J. (2008). Parental involvement in homework: A research synthesis. Review of Educational Research, 78(4), 1039-1101. doi:10.3102/0034654308325185.

Pérez Campos, G. (2004). What are cultural models for? Child-rearing practices in historical perspective. Culture \& Psychology, 10(3), 279. doi:10.1177/1354067X04042889.

Rogoff, B. (2003). The cultural nature of human development. Oxford: OUP.

Solomon, Y., Warin, J., \& Lewis, C. (2002). Helping with homework? Homework as a site of tension for parents and teenagers. British Educational Research Journal, 28(4), 603-622. doi:10.1080/ 0141192022000005850 .

Strauss, C. (1992). What makes Tony run? Schemas as motives reconsidered. In R. D'Andrade \& C. Strauss (Eds.), Human motives and cultural models (pp. 197-224). Cambridge: Cambridge University Press.

Street, B., Baker, D., \& Tomlin, A. (2005). Navigating numeracies: Home/school numeracy practices. UK: Springer.

Williams, P. (2008). Independent review of mathematics teaching in early years settings and primary schools. Department for Children, Schools and Families, UK.

Zittoun, T. (2004). Symbolic competencies for developmental transitions: The case of the choice of first names. Culture \& Psychology, 10(2), 131-161. doi:10.1177/1354067X04040926.

Zittoun, T. (2006). Transitions: Development through symbolic resources. Greenwich: Information Age Publishing. 